\section{Amitriptyline Use for Acute Pain in Remote Environments}

To the Editor:

In light of the recent publication on treatment of acute pain in remote environments, ${ }^{1}$ we would like to draw readers' attention to another possible nonnarcotic analgesic that may be helpful in the wilderness setting. Although not mentioned in the recent guidelines, tricyclic antidepressants (TCAs), specifically amitriptyline, have been described as useful for acute neuropathic pain control in nonfreezing cold injury (NFCI). Considering the international application of the Wilderness Medical Society guidelines in up-to-date evidence-based practice, we feel that brief discussion of amitriptyline is warranted.

As pain comprises several physiologic components and pathways (nociceptive, neuropathic, and central), differentiation of the specific component or pathway signal is key to the effective treatment of both acute and subacute or chronic pain. Classically, A-delta fiber-mediated and C fibermediated nociceptive pain is both simultaneous and proportional to the inciting cause, and may be described as aching, throbbing, or sharp in character. Nociceptive pain predominates the acute pain state. In contrast, neuropathic and central pain pathways involve both primary and secondary hyperalgesia, evolve to include such pain types as allodynia and dysesthesia, and may be described as shooting, electric, or burning in character. ${ }^{2}$ Although typically thought of as predominant in subacute or chronic pain, it is important to recognize the impact of neuropathic and central pain components in the acute pain state as well, particularly given the fact that conventional analgesics are frequently ineffective in their treatment. We applaud the authors of the recent guidelines for acknowledging this in their discussion of the frequent association and potential role of anxiety, depression, and sleep disruption in acute pain. ${ }^{1}$

Amitriptyline is considered a first-line therapeutic agent for the treatment of neuropathic pain in both the United States and the United Kingdom. Typical analgesic doses range from 10 to $50 \mathrm{mg}$. Antihistaminergic and anticholinergic effects predominate at lower analgesic doses, whereas serotonergic and noradrenergic effects come into play at higher antidepressant doses. This suggests the mechanism for pain relief with TCAs may involve anti-inflammatory and sedative central pathways.

A Cochrane review reports there is a reasonable body of second-tier evidence supporting the efficacy of amitriptyline for control of neuropathic pain (Number Needed to Treat $[\mathrm{NNT}]=4$ ). Although there is a lack of top-tier evidence, it is "balanced against decades" of successful clinical utility of TCAs for neuropathic and central pain management. ${ }^{3}$ Recently reviewed in the
European literature ${ }^{4}$ and considered a standard first-line treatment in the armed forces of the United Kingdom, ${ }^{5}$ the use of amitriptyline for NFCI pain management also appears in US military medical texts as early as $2001{ }^{6}$

Other publications support the use of amitriptyline both early in the treatment of $\mathrm{NFCI}^{7}$ as well as later in its course. ${ }^{4}$ Although amitriptyline remains the most commonly cited medication for neuropathic pain resulting from cold injuries, there is current interest in other TCAs with more favorable side effect profiles, namely nortriptyline and desipramine, for control of acute neuropathic pain. Established expedition and mountain medicine experts in the United Kingdom have current interest in the potential utility of anticonvulsants such as gabapentin and antidepressants such as duloxetine in pain management of NFCI (e-mail communication, Dr P. Richards, March 2014).

Amitriptyline has indeed been used by one of us (R.W.) for treatment of neuropathic pain in a deployed military setting. His experience using amitriptyline in doses ranging from 10 to $50 \mathrm{mg}$ orally at night as an adjunctive medication for successful control of acute nocturnal neuropathic pain in tropical and desert immersion foot and traumatic partial amputation is worth anecdotally noting, and suggests the use of TCAs may be worth exploring for the treatment of acute neuropathic pain components in other injuries relative to wilderness and environmental medicine.

In summary, we appreciate the review and grading of evidence for the medications mentioned in the recent guidelines, but would like to point readers' attention to an unmentioned class of drugs that may be beneficial in the wilderness setting as an adjunctive treatment for acute pain, the TCAs.

Jeremy Joslin, MD

Department of Emergency Medicine

State University of New York Upstate Medical University

Syracuse, NY

Robert Worthing, MD

Division of Physical Medicine \& Rehabilitation

University of Utah

Salt Lake City, UT

Matthew Ladbrook, MBChB

Yew Tree Medical Centre

Solihull, UK

Joshua Mularella, DO

Department of Emergency Medicine

State University of New York Upstate Medical University

Syracuse, $N Y$ 


\section{References}

1. Russell KW, Scaife CL, Weber DC, et al. Wilderness Medical Society practice guidelines for the treatment of acute pain in remote environments. Wilderness Environ Med. 2014;25:41-49.

2. Braddom RL. Physical Medicine and Rehabilitation. 4th ed. Philadelphia, PA: Saunders Elsevier; 2010.

3. Moore RA, Derry S, Aldington D, Cole P, Wiffen PJ. Amitriptyline for neuropathic pain and fibromyalgia in adults. Cochrane Database Syst Rev. 2012;12:CD008242.

4. Hallam M-J, Cubison T, Dheansa B, Imray C. Managing frostbite. BMJ. 2010;341:c5864.

5. Imray CHE, Castellani JW. Nonfreezing cold-induced injuries. In: Auerbach PS, ed. Wilderness Medicine. 6th ed. Philadelphia, PA: Elsevier Mosby; 2011:178.

6. Thomas JR, Oakley EHN. Nonfreezing cold injury. In: Pandolf KB, Burr RE, eds. Textbook of Military Medicine, Medical Aspects of Harsh Environments. Vol 1. Washington, DC: US Army; 2001:467-490.

7. Johnson C, Oakley H. Cold climates. In: Johnson C, Anderson SR, Dallimore J, Winser S, Warrell DA, eds. Oxford Handbook of Expedition and Wilderness Medicine, Oxford, UK: Oxford University Press; 2008:579-606.

\section{In Response to WMS Pain Management Guidelines}

\section{To the Editor:}

I appreciated the brief overview of analgesia treatment in the Wilderness Medical Society practice guidelines for the treatment of acute pain in remote environments by Russell et al. ${ }^{1}$ However, a few additional medications and comments may help guide wilderness medicine providers when choosing pain medication for a medical kit.

Regarding choice of nonsteroidal anti-inflammatory drug (NSAID), meloxicam is worth special mention because of once-a-day dosing, less gastrointestinal toxicity, and less platelet inhibition compared with others. It is the oral NSAID of choice for the tactical combat casualty care trauma pack. Also, if one chooses to carry 2 NSAIDs, it may be prudent to bring 2 from different classes. $^{2-4}$

Tramadol is an option for acute pain; it is not classified as an opiate or controlled substance in the United States-thus making travel across international borders easier and providing an oral nonopiate option to NSAIDS and acetaminophen.

Corticosteroids such as prednisone and dexamethasone are useful for acute pain when administered orally, intramuscularly, or intra-articularly. That is noteworthy because the latter drug is a staple in most high altitude medical kits. ${ }^{5,6}$
For adjunctive medications, nonbenzodiazepine skeletal muscle relaxers, like tizanidine, cyclobenzaprine, and methocarbamol, are useful for acute low back pain and acute strains and spasms of joint muscles, such as with a shoulder dislocation. ${ }^{7}$

Topical medications may be useful, particularly for marine or pediatric medical kits. Two notable formulations include lidocaine/prilocaine cream (primarily used as an anesthetic but as an analgesic too) and NSAID creams, which can be used alone or compounded with other topical analgesics such as ketamine, lidocaine, gabapentin, and muscle relaxants.

Specific ophthalmologic, otic, and dental medications for acute pain are also important considerations, as specialized pain medications may eliminate the need for more risky and less-effective systemic medications.

As an aside, Russell et $\mathrm{al}^{1}$ duly made a note about third-party prescribing with regard to oral opiates. In the United States and in certain other countries, that usually applies to all prescription medicine, not just to opiates. Therefore, this excellent advice should apply to all prescription medicines, not just to opiates.

Christopher Van Tilburg, MD Occupational and Travel Medicine and Mountain Emergency Services Providence Hood River Memorial Hospital Crag Rats Mountain Rescue Hood River, OR

\section{References}

1. Russell W, Scaife CL, Weber DC, et al. Wilderness Medical Society practice guidelines for the treatment of acute pain in remote environments. Wilderness Environ Med. 2014;25: 41-49.

2. Singh G, Lanes S, Steinbrü G, Triadafilopoulos G. Gastrointestinal tolerability of meloxicam compared to diclofenac in osteoarthritis patients. Am J Med. 2004;117:100-106.

3. Wedmore IS, Johnson T, Czarnik J, et al. Pain management in the wilderness and operational setting. Emerg Med Clin North Am. 2005;23:583-601.

4. United States Army Institute of Surgical Research. Tactical combat casualty care guidelines, 28 October 2013. Available at: http://www.usaisr.amedd.army.mil/assets/pdfs/ tccc_guidelines_131028.pdf. Accessed April 18, 2014.

5. Holve RL, Barkan H. Oral steroids in initial treatment of acute sciatica. J Am Board Fam Med. 2008;21:469-474.

6. Vyvey M. Steroids as pain relief adjuvants. Can Fam Phys. 2010;56:1294-1297.

7. Casazza BA. Diagnosis and treatment of acute low back pain. Am Fam Physician. 2012;85:343-350. 